\title{
Restrictive Lung Disease
}

National Cancer Institute

\section{Source}

National Cancer Institute. Restrictive Lung Disease. NCI Thesaurus. Code C91762.

Decreased lung volume and inadequate ventilation due to parenchymal lung disorders

(e.g., interstitial pulmonary fibrosis) or extrapulmonary disorders (e.g., scoliosis). Patients present with shortness of breath and cough. 